\title{
Popliteal catheter placement utilizing ultrasound needle guidance system
}

\author{
This article was published in the following Dove Press journal: \\ Local and Regional Anesthesia \\ 28 July 2010 \\ Number of times this article has been viewed
}

\author{
Steven R Clendenen \\ Christopher B Robards \\ Roy A Greengrass \\ Mayo Clinic, Jacksonville, Florida, USA
}

\begin{abstract}
While ultrasound (US)-guided placement of peripheral nerve blocks is rapidly gaining popularity, expert practitioners agree that two of the most significant barriers to safety and efficacy are keeping the needle tip within the image and unintentional probe movement during the procedure. ${ }^{1}$ In addition, placing a nerve catheter past the needle tip under direct US observation requires two practitioners: one to hold the US probe and needle and another to advance the catheter. We present a case of a needle guidance system that attaches to the ultrasound probe and facilitates in-plane imaging. It enables a single practitioner to successfully execute a popliteal sciatic nerve block and visualize catheter placement. Therefore, a needle guidance system may represent an additional modification to ultrasound imaging that increases both time efficiency as well as safety.
\end{abstract}

Keywords: needle guidance system, popliteal sciatic nerve catheter, ultrasound

\section{Case report}

A 30-year-old man with no significant past medical history was scheduled for tibial rod removal and possible bone graft of the ankle. The patient received a single injection femoral and a continuous popliteal sciatic nerve block in the holding area for postoperative pain management.

The patient was positioned prone, and an axial ultrasound (US) image of the sciatic nerve was obtained $8 \mathrm{~cm}$ superior to the popliteal crease. The needle guidance system by Philips Ultrasound System HD-11 ${ }^{\mathrm{TM}}$ with 12-3 linear probe (Philips Medical Systems; Andover, MA) was used to measure the distance from the needle holder to the nerve. This system highlights the needle trajectory on the US image with superimposed dotted lines and secures a precise in-plane view of the needle. When the biopsy guide is activated on the HD-11 US system, it produces a thick blue crosshair. The track ball can control the needle length crosshair, displaying the distance from the top of the needle guide to the target. It was $6.9 \mathrm{~cm}$ (Figure 1). This system highlights the needle trajectory on the US image with superimposed dotted lines and secures a precise inplane view of the needle (Figure 2).

The advancement of the $17 \mathrm{~g}$ plexus block needle has centimeter markings that concur with the markings on the US system and distance to the target nerve can be continuously calculated with needle advancement. The patient was prepped, draped, and a sterile US probe cover was applied. The guidance system is a disposable, sterile, plastic attachment for the US probe that contains a needle holder in line with the center of the US beam.
Correspondence: Steven R Clendene

Jacksonville, FL 32224

$\mathrm{Tel}+\mathrm{I}$ 904-956-3327

Fax + I 904-956-3332

Email clendenen.steven@mayo.edu 


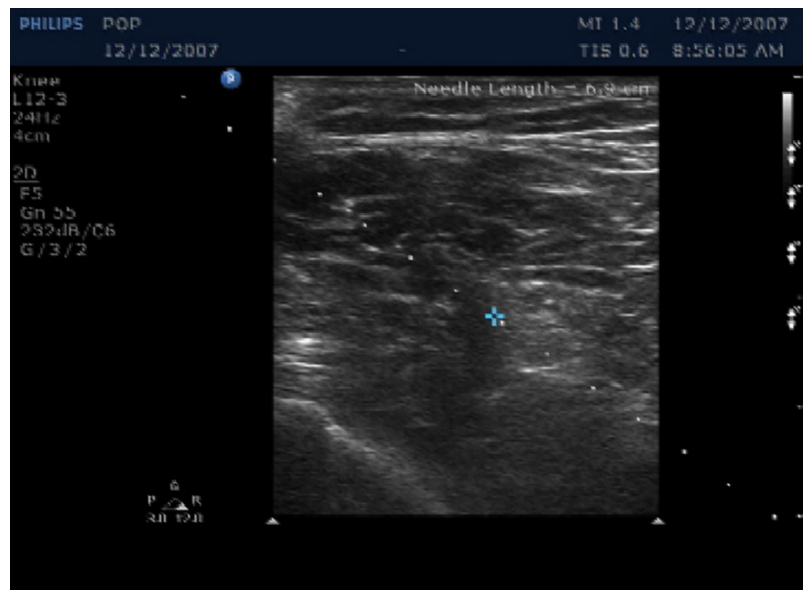

Figure I Axial ultrasound (US) image of the popliteal sciatic nerve with the needle guidance system activated highlighting the projected needle trajectory to the nerve. Philips Ultrasound System HD II with I2-3 linear probe (Philips Medical Systems; Andover, MA).

The Arrow International (Reading, PA) $17 \mathrm{~g} \times 3.5$ inch insulated tuohy needle under simultaneous real-time US visualization and nerve stimulation of 1.0 milliamp $(\mathrm{mA})$ observed tracking exactly along the dotted guide line that was displayed on the screen (Figure 3). In addition to maintaining an in-plane view, the needle and probe function as one unit, helping to secure the US probe placement.

Tibial motor response was evident at a depth of $8 \mathrm{~cm}$ and $0.40 \mathrm{~mA}$. The needle position was maintained solely by holding the US probe (Figure 4). Then the needle stylet was removed and an Arrow StimCath ${ }^{\mathrm{TM}}$ (Reading, PA) catheter was advanced with continuous visualization and nerve stimulation. After securing the catheter in place, $30 \mathrm{~mL}$ of $0.5 \%$ ropivacaine was injected. A hypoechoic ring of local anesthesia was visible surrounding the nerve.

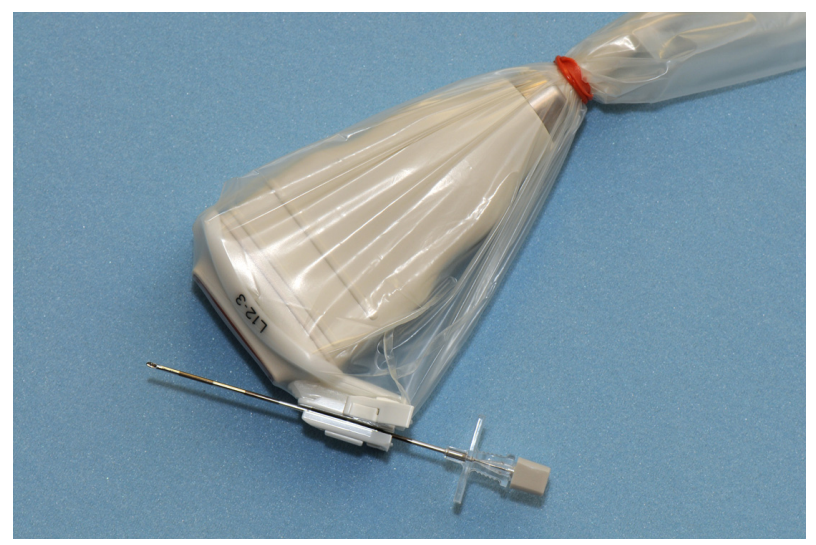

Figure 2 Draped nondisposable component of the Ultra-Pro II $^{\mathrm{TM}}$ Needle Guide (CIVCO; Kalona, IA USA) covering a 12-3 linear ultrasound probe (Philips Medical Systems; Andover, MA) with a $17 \mathrm{~g} \times 3.5$ inch insulated tuohy needle (Arrow International, Reading, PA) inserted through the disposable portion of the Ultra-Pro II ${ }^{\mathrm{TM}}$ Needle Guide.

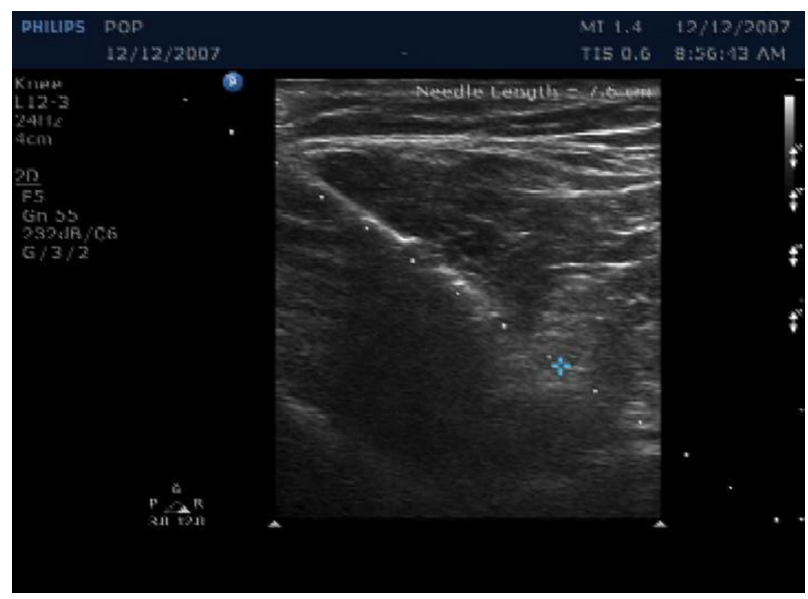

Figure 3 Axial ultrasound (US) image of the popliteal sciatic nerve with the needle aligned with the projected needle trajectory course to the nerve. Philips Ultrasound System HD II with I2-3 linear probe (Philips Medical Systems; Andover, MA).

The patient was then repositioned supine, and a single injection femoral nerve block was performed. A 2 inch, $22 \mathrm{~g}$ B-Braun (Bethlehem, PA) Stimuplex ${ }^{\circledR}$ PTFE insulated needle was percutaneously advanced $1 \mathrm{~cm}$ lateral to the femoral artery with electrostimulation. Patellar snap was evident to $0.40 \mathrm{~mA}$, and the practitioner incrementally injected $20 \mathrm{~mL}$ of $0.5 \%$ ropivacaine.

Ten minutes after completion of the femoral nerve block, testing revealed absence of sensation in both the femoral and sciatic distribution. Both leg extension, plantar, and dorsal flexion were absent.

The patient received laryngeal mask general anesthesia for the procedure, and the pain scores in the recovery room were $0 / 10$. The patient was discharged to home with an I-Flow On-Q On Demand (Lake Forest, CA) disposable infusion device. Daily telephone contact

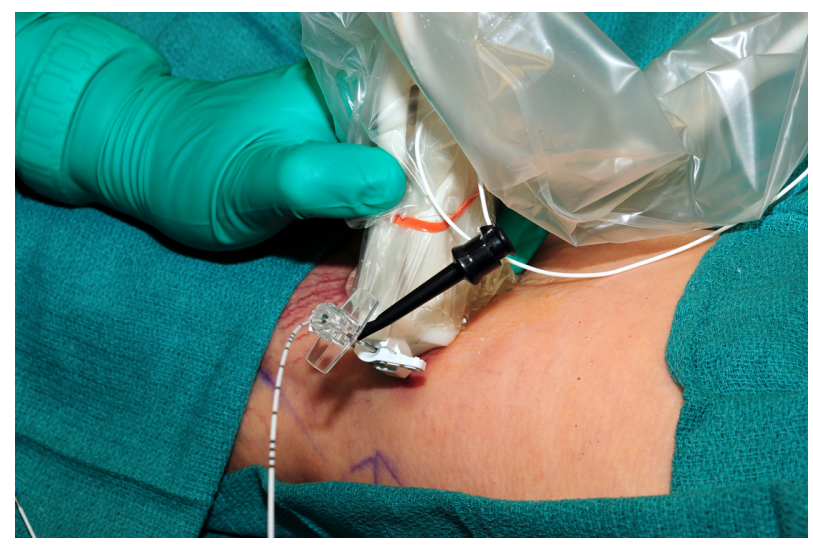

Figure 4 Popliteal sciatic nerve catheter (StimCath ${ }^{T M}$, Arrow International, Reading, PA) advancement with the needle position maintained by the needle guide attached to the US probe with the patient prone. 
revealed excellent analgesia requiring one dose of $\mathrm{PO}$ narcotics on postoperative day 1 . The patient was maintained on acetaminophen after discontinuation of the peripheral nerve catheter on postoperative day 5. Surgical follow-up revealed return to full activities by four weeks postoperation.

\section{Discussion}

Recent opinion on US guidance has revealed that it may not eliminate complications of nerve blocks. In fact, there have been several case reports of intraneural and intravascular injection during blocks, despite the adjunct use of US. ${ }^{2-4}$ Although complications have been reported, researchers have also revealed that use of US can improve block placement times as well as block onset times. ${ }^{5-8}$ Ultrasound difficulties have been well delineated. These include clinician expertise, maintenance of an exact in-plane view, artifacts, and pitfall errors. Of these, one of the most troublesome is keeping the needle tip in view. ${ }^{1}$

One solution may be to devise user-friendly needle guides that secure the needle track in line with the US beam. Though in-plane visualization is widely accepted as the safest way to conduct US blocks, it can be very difficult to obtain a precise in-plane view and to ensure a safe location of the needle tip. Physicians have tried a variety of methods from cameras to lasers in order to combat this very problem. ${ }^{9-11}$ Radiography literature reveals good success with needle guides, especially when targets are small or conventional methods have failed. ${ }^{12}$

An additional advantage of the needle guide is that the imaging system and the delivery system become one unit. The practitioner fastens the needle guide, containing the track needle, securely onto the ultrasound probe. The practitioner can hold the probe with one hand and control the needle with the second hand. Instead of requiring a third hand for the catheter, one practitioner can release the needle because the needle guide holds it in a stable relationship with both the tissue planes and the US beam. A common practice today is to guide the needle to the nerve with US, but set the probe aside and blindly advance the catheter. US guidance allows the visualization of catheter advancement and its relationship to the nerve. The Arrow Stim Catheter has a metal inner coil and tip that is echogenic and enhances visualization of catheter advancement. The sciatic nerve is a fairly mobile structure in which the pressure applied from the US probe during scanning will displace the nerve. When the needle is positioned adjacent to the target, it is not uncommon to observe the nerve move several centimeters with removal of the US probe for catheter advancement, which may explain secondary block failure.

We have performed over 20 successful popliteal nerve catheters using the US needle guidance system. We found it easy to use; the needle tracking was precise and the target depth was accurate. The limitation of the needle guide is that once the practitioner initiates a trajectory, he or she can only make minor adjustments. The precision of the image and tract must be pristine prior to cutaneous puncture. In addition, there are only a few trajectories preprogrammed into the US machine; therefore, one must be more adept at acquiring an US image. In other words, not only must the target nerve appear in the image, but it must also be in direct alignment with a path predetermined by the needle holder. In this case report, the needle guide only had one available trajectory, but other models allow a greater selection of four trajectory lines. These other models allow clinicians to change the trajectory to match the target in the US image instead of adjusting the US image to follow a different path.

Aside from the trajectory restrictions, the physical design also limits the needle guidance system. Each probe must have its own custom needle guide. First, the footprints of the different probes are different sizes. Second, in order to overlay the trajectory on a live image, the practitioner must synchronize the needle guide with the US machine software. Also, increasing the size of the probe by adding an additional fixture is likely to hamper efforts in block areas that are already compromised by an unusual probe angle or a small anatomic space. Despite the aforementioned weaknesses, the needle guide remains a simple adjunct to increasing block success and has a long, proven history in other medical specialties. The role of US in peripheral nerve blocks continues to evolve rapidly, but in each case, success and safety partly depends on needle tip identification within tissue. The needle guidance systems are one way to improve that visibility; especially with novice clinicians.

\section{Disclosure}

The authors report no conflicts of interest in this work.

\section{References}

1. Sites BD, Spence BC, Gallagher JD, Wiley CW, Bertrand ML, Blike GT. Characterizing novice behavior associated with learning ultrasound-guided peripheral regional anesthesia. Reg Anesth Pain Med. 2007;32:107-115.

2. Loubert C, Williams SR, Helie F, Arcand G. Complication during ultrasound-guided regional block: accidental intravascular injection of local anesthetic. Anesthesiology. 2008;108:759-760.

3. Russon K, Blanco R. Accidental intraneural injection into the musculocutaneous nerve visualized with ultrasound. Anesth Analg. 2007; 105:1504-1505. 
4. Schafhalter-Zoppoth I, Zeitz ID, Gray AT. Inadvertent femoral nerve impalement and intraneural injection visualized by ultrasound. Anesth Analg. 2004;99:627-628.

5. Chan VW, Perlas A, McCartney CJ, Brull R, Xu D, Abbas S. Ultrasound guidance improves success rate of axillary brachial plexus block. Can J Anaesth. 2007;54:176-182.

6. Koscielniak-Nielsen ZJ. Ultrasound-guided peripheral nerve blocks: what are the benefits? Acta Anaesthesiol Scand. 2008;52:727-737.

7. Orebaugh SL, Williams BA, Kentor ML. Ultrasound guidance with nerve stimulation reduces the time necessary for resident peripheral nerve blockade. Reg Anesth Pain Med. 2007;32:448-454.
8. Perlas A, Brull R, Chan VW, McCartney CJ, Nuica A, Abbas S. Ultrasound guidance improves the success of sciatic nerve block at the popliteal fossa. Reg Anesth Pain Med. 2008;33:259-265.

9. Bradley MJ. An in-vitro study to understand successful free-hand ultrasound guided intervention. Clin Radiol. 2001;56:495-498.

10. Khosravi S, Rohling R, Lawrence P. One-step needle pose estimation for ultrasound guided biopsies. Conf Proc IEEE Eng Med Biol Soc. 2007:3343-3346.

11. Tsui BC. Facilitating needle alignment in-plane to an ultrasound beam using a portable laser unit. Reg Anesth Pain Med. 2007;32:84-88.

12. Marhofer $P$, Chan VW. Ultrasound-guided regional anesthesia: current concepts and future trends. Anesth Analg. 2007;104:1265-1269.

\section{Publish your work in this journal}

Local and Regional Anesthesia is an international, peer-reviewed, open access journal publishing on the development, pharmacology, delivery and targeting and clinical use of local and regional anesthetics and analgesics. The journal welcomes submitted papers covering original research, basic science, clinical studies, reviews \& evaluations,

\section{Dovepress}

guidelines, expert opinion and commentary, case reports and extended reports. The manuscript management system is completely online and includes a very quick and fair peer-review system, which is all easy to use. Visit http://www.dovepress.com/testimonials.php to read real quotes from published authors. 